\title{
Aprendizagem Baseada em Projetos no Ensino de Física: uma Revisão da Literatura
}

\section{Project-Based Learning in Physics Education: a Literature Review}

\author{
Terrimar Ignácio Pasqualetto ${ }^{(0)}$ Brasil \\ Eliane Angela Veit ${ }^{\circledR}$ Brasil \\ Ives Solano Araujo ${ }^{(1)}$ Brasil
}

Este trabalho apresenta uma revisão da literatura sobre a Aprendizagem Baseada em Projetos (ABP) no contexto do Ensino de Física. O objetivo é apresentar uma breve revisão histórica da $\mathrm{ABP}$ e traçar um panorama das publicações da área a fim de identificar e descrever as principais concepções e orientações metodológicas a respeito da ABP, bem como os referenciais teóricos de aprendizagem e metodologias de pesquisa que têm sido utilizados. Os resultados apontam predominância da metodologia qualitativa nas pesquisas sobre o tema, considerável dispersão das concepções e orientações metodológicas e preocupante descuido acerca dos referenciais teóricos de aprendizagem.

Palavras-chave: Ensino de Física; Aprendizagem Baseada em Projetos.

This work presents a literature review on Project-Based Learning (PBL) in the context of Physics Education. It aims at both presenting a brief historical review of PBL and providing an overview of the publications in this field in order to identify and describe the main concepts and methodological guidelines for PBL, as well as the theoretical frameworks and research methodologies that have been used. The results show the prevalence of qualitative methodology in the research on this subject, considerable dispersion of concepts and methodological guidelines, and recklessness concerning the theoretical frameworks.

Keywords: Physics Education; Project-Based Learning.

\section{Introdução}

As necessidades formativas do cidadão do século XXI vão muito além da acumulação de conhecimentos. Envolvem, entre outras, a capacidade de seleção e tratamento de informações, a transposição de conhecimento de uma situação e/ou contexto para outro, a resolução de problemas para os quais não está estabelecida uma 
resposta e a capacidade de trabalhar de forma cooperativa. Apesar disso, e das limitações de estratégias didáticas baseadas quase que exclusivamente na apresentação oral do conteúdo, o chamado ensino tradicional é ainda muito presente no ambiente escolar.

São indispensáveis, portanto, alternativas metodológicas que coloquem a escola em consonância com as características e necessidades da sociedade. Neste sentido, de longa data tem crescido a diversidade de metodologias ativas, que procuram trazer o aluno para o centro do processo educativo, como agente da sua própria aprendizagem. São exemplos de tais metodologias, o Ensino sob Medida, originalmente denominado de Just-in-Time Teaching, (Novak, Gavrin, Christian, \& Patterson, 1999), a Instrução pelos Colegas ou Peer Instruction (Mazur, 2015), a Aprendizagem Baseada em Equipes ou Team-Based Learning (Michaelsen, Knight, \& Fink, 2004), a Aprendizagem Baseada em Projetos ou Project-Based Learning (Bender, 2014), entre outras.

Dentre essas, pode-se destacar a Aprendizagem Baseada em Projetos (ABP) como uma metodologia cujo potencial envolve não só o trabalho colaborativo, como também o desenvolvimento da capacidade de resolução de problemas abertos e a interdisciplinaridade. Segundo Bender (2014, p.15),

[...] a ABP pode ser definida pela utilização de projetos autênticos e realistas, baseados em uma questão, tarefa, ou problema altamente motivador e envolvente, para ensinar conteúdos acadêmicos aos alunos no contexto do trabalho cooperativo para a resolução de problemas.

A ABP tem se mostrado capaz de envolver os estudantes em investigações que ultrapassam os limites da sala de aula e que, além da aprendizagem acadêmica, proporcionam motivação, engajamento e, em muitos casos, contribuições à comunidade na qual os alunos estão inseridos (Bender, 2014). Essas características, desejadas por todos os ramos da educação, podem ser especialmente úteis em disciplinas costumeiramente consideradas difíceis e de baixo interesse para grande parte dos alunos da educação básica.

Entre tais disciplinas é possível destacar a Física como uma matéria escolar cuja imagem junto aos egressos do Ensino Médio, período em que normalmente há um primeiro contato efetivo com seu conteúdo, costuma remeter a recordações desagradáveis (Bonadiman \& Nonenmacher, 2007; Menegotto \& Rocha Filho, 2008). Ao mesmo tempo, é inegável a sua importância na formação do estudante frente a uma sociedade tecnológica em pleno desenvolvimento, exigindo de seus cidadãos características desenvolvidas no estudo da Física, como capacidade de resolução de problemas, compreensão de grandezas físicas presentes no dia a dia, compreensão dos fenômenos físicos cotidianos e de suas possíveis consequências. Nesta direção, a $\mathrm{ABP}$ se apresenta como uma alternativa metodológica com potencial para evitar problemas usuais do ensino de Física, e ainda contribuir para o desenvolvimento de outras capacidades como responsabilidade social, uso de ferramentas tecnológicas e transposição do conhecimento em diferentes contextos.

Sendo assim, propõe-se aqui uma revisão da literatura acerca da ABP no contexto 
do Ensino de Física. Pretende-se com isso obter um panorama sobre o que a literatura da área já dispõe a respeito da $\mathrm{ABP}$, compreender a metodologia e sua origem histórica e oferecer ao leitor um resumo da literatura para que pesquisadores e interessados na implementação da ABP disponham de um recurso para orientação das suas ações. Para tanto, a presente revisão da literatura foi organizada a partir das seguintes questões de pesquisa:

- Qual o perfil da produção acadêmica a respeito da ABP no contexto do Ensino de Física?

- Quais as principais concepções e orientações metodológicas acerca da ABP?

- Quais os referenciais teóricos de aprendizagem e as metodologias de pesquisa associadas com a ABP?

Nas próximas seções são apresentados, sucessivamente, uma breve revisão da trajetória histórica da ABP, a metodologia de seleção dos artigos, os achados relativos a cada uma das questões de pesquisa e os comentários finais.

\section{Trajetória histórica da ABP e possíveis consequências sobre suas características na atualidade}

A origem do trabalho educacional com projetos costuma ser remetida ao Ensino por Investigação ou Inquiry, que por sua vez foi fortemente influenciado pelas ideias do filósofo e pedagogo americano John Dewey (Dewey, 1899; Zômpero \& Laburú, 2011). Nesta versão histórica cita-se ainda William Heard Kilpatrick, considerado por muitos o pai da Pedagogia Baseada em Projetos (Quintana-Nedelcos \& Llovera-González, 2009).

Embora essa seja a origem mais reportada para o uso educacional de projetos, Knoll (1997) considera que o trabalho com projetos teria se iniciado no final do século XVI, em escolas de arquitetura da Europa, sendo posteriormente transplantado para a América, onde foi inserido sucessivamente em cursos de Engenharia, na Escola de Formação Manual e nas escolas primárias. Após isso, o método de projetos teria sido redefinido por Kilpatrick e levado de volta para a Europa sob influência dessas redefinições. Por fim, teria ocorrido uma redescoberta da ideia de projeto e uma nova onda de divulgação internacional que se estende até o presente momento. A Figura 1 mostra a cronologia defendida por Knoll (1997).

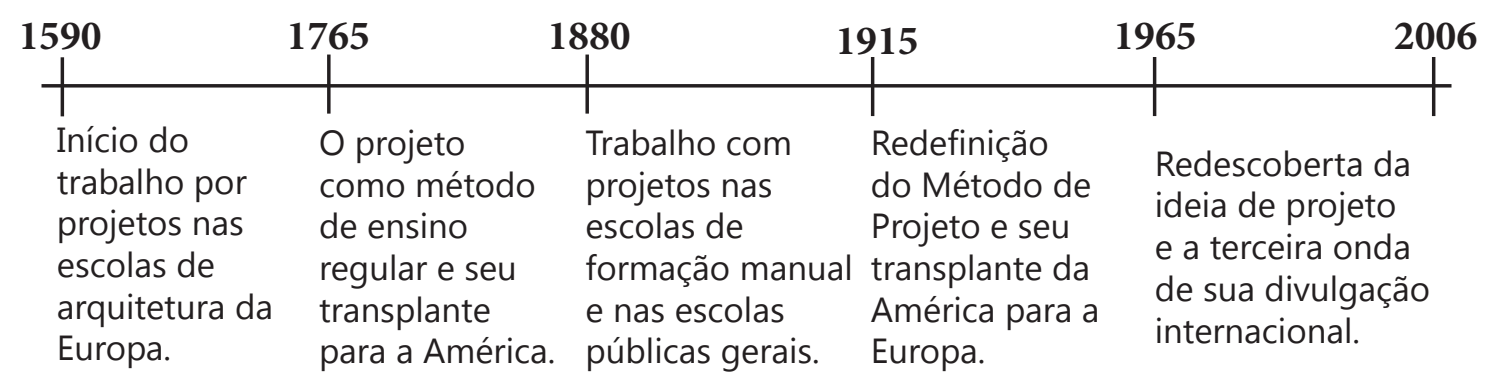

Figura 1. Cronologia dos projetos defendida por Knoll (1997, p. 2). 
Enquanto alguns autores atribuem a Dewey a origem do método de projetos, Knoll (1997) o apresenta como participante de uma discussão a respeito desse método. A versão de Knoll (1997) não nega a influência de Dewey e Kilpatrick, mas dá-lhe uma nova interpretação, afinal "a percepção de que a aprendizagem através de projetos começou trezentos anos mais cedo do que é normalmente assumido abre novas perspectivas para a sua interpretação" (Knoll, 1997, p.2).

Segundo Knoll (1997), em 1879 é fundada a Escola de Formação Manual em St. Louis (EUA), onde foi implementado o chamado "Sistema Russo de Instrução". Nesse sistema, os alunos primeiramente passavam por uma série de exercícios básicos, aprendendo o uso de ferramentas e técnicas e ao final de cada unidade de ensino recebiam tempo para desenvolver e realizar seu projeto.

Dewey, no entanto, acreditava que a "construção" do projeto não deveria ser o objetivo final do processo educacional, mas sim, o momento da aprendizagem. Portanto, a "instrução" não deveria preceder o projeto, mas estar integrada a ele (Knoll, 1997, p.4). É nesse ponto, em meados de 1915, que as duas visões históricas se encontram, apesar de divergirem nos detalhes. Nesta época Dewey era o grande nome do movimento chamado de Escola Nova nos Estados Unidos, que buscava uma renovação no ensino e entre suas premissas, a oposição ao modelo tradicional de transmissão de conteúdos descontextualizados e sem significado para os alunos. Como alternativa ao modelo tradicional Dewey teria sistematizado a Pedagogia de Projetos, sendo Kilpatrick o responsável pelo seu encaminhamento metodológico e sua popularização na primeira metade do século XX (Oliveira, 2006).

Na verdade, o que Kilpatrick fez foi redefinir o conceito de projeto tomando como base a teoria da experiência de Dewey, ou seja, a ideia de que "as crianças adquiram experiência e conhecimento pela resolução de problemas práticos, em situações sociais" (Oliveira, 2006, p. 9).

Kilpatrick tomou então a psicologia da criança como elemento crucial no processo de aprendizagem defendendo que sua motivação e o sucesso de sua aprendizagem aumentariam na medida em que ela perseguisse seus próprios objetivos (Knoll, 1997). Isso, associado à influência da psicologia da aprendizagem de Edward L. Thorndike (Meltzer \& Otero, 2015), levou Kilpatrick a defender que "as crianças tinham que ser capazes de decidir livremente o que queriam fazer" (Knoll, 1997, p. 5). Essas ideias associadas fizeram com que redefinisse o projeto como um ato proposital genuíno. Essa definição não só permitia que praticamente tudo que fosse feito propositadamente pela criança pudesse ser considerado um projeto, como estabelecia o projeto como um empreendimento apenas do aluno e não uma iniciativa conjunta do professor com o aluno. Essa definição gerou resistências e críticas inclusive de Dewey (Knoll, 1997; Oliveira, 2006).

Dewey defendia que um projeto deveria ser uma iniciativa conjunta da criança com o professor. Para ele, as crianças precisam do auxílio de um professor para garantir o processo contínuo de aprendizagem e crescimento. Além disso, discordava 
de Kilpatrick quanto à definição de projeto como uma atividade intencional. Segundo ele, "um propósito genuíno começa com um impulso, mas difere-se de um impulso original e de um desejo através da sua transformação em um plano e em um método de ação" (Dewey, 1938, p. 43 citado em Knoll, 1997, p. 6). Portanto, Dewey, bem como os principais educadores americanos, mantiveram a ideia tradicional de projeto rejeitando a concepção mais ampla defendida por Kilpatrick (Knoll, 1997).

Essas críticas geraram um efeito de amortecimento na popularidade do método de projeto. No entanto, a visão ampla do Método de Projetos, defendida inicialmente por Kilpatrick, já havia sido disseminada em diversos países da Europa e da América Latina. Por volta de 1920, os projetos passaram a ser divulgados junto a educadores russos e em 1930 já era considerado por alguns deles como o método democrático de ensino. Neste período, o Método de Projetos ainda estava muito relacionado com a formação profissional e decisões políticas da então União Soviética impediram a sua adoção como metodologia oficial, ocasionando uma parada abrupta das discussões sobre o tema (Knoll, 1997).

As ideias de Dewey e Kilpatrick ficaram “congeladas” após a Segunda Guerra Mundial em função do progresso do condutismo e da psicometria, bem como em razão da nova situação socioeconômica mundial (Hernández, 1998). No final da década de 60, as discussões sobre projetos foram retomadas na Europa, especialmente na Alemanha onde se concentrou a maior parte desses debates. Apesar de a Alemanha ser o centro das discussões, países do norte europeu também participaram delas. A Dinamarca foi um desses países, formando-se lá uma tradição na Pedagogia de Projetos aplicada ao ensino das engenharias. Neste país, na década de 70, foram criadas duas universidades que implementaram e institucionalizaram os princípios da Pedagogia de Projetos mostrando que o modelo era viável (Graaff \& Kolmos, 2007).

Também na década de 60, com o sucesso das ideias de Piaget sobre o desenvolvimento da inteligência e sobre o papel da aprendizagem de conceitos nos Estados Unidos, o uso dos projetos foi retomado sob o nome de Trabalho por Temas. Motivado pelo questionamento sobre que conceitos ensinar e como selecioná-los, Bruner propôs "[...] que o ensino deveria centrar-se em facilitar o desenvolvimento de conceitos-chave a partir das estruturas das disciplinas." (Hernández, 1998, p. 69). Sendo assim, os projetos, ou o trabalho por temas, se tornaram uma alternativa para levar essa proposta para a sala de aula.

Apesar disso, a proposta de Bruner dava margem a questionamentos a respeito de alguns aspectos desse enfoque do currículo: o fato de as diferenças entre disciplinas não ser levado em conta, o fato de diversas ideias-chave não serem facilmente representadas e nem os alunos serem capazes de compreendê-las sem uma base organizada de conhecimentos (Hernández, 1998).

$\mathrm{Na}$ década de 80, ocorreu a revolução cognitiva na forma de compreender o ensino e as mudanças na concepção sobre o conhecimento. Esses fatos, associados à nova situação da economia mundial, levaram a uma série de mudanças na educação 
escolar e fizeram com que os projetos novamente se tornassem objeto de interesse.

As mudanças deste período deram força a aspectos como a visão construtivista sobre aprendizagem, o contexto da aprendizagem, a importância da participação e da interação entre alunos e desses com a comunidade, a relevância das estratégias metacognitivas no processo de aprendizagem, entre outros. Todos esses fatores ressaltam a natureza complexa e não linear do processo de aprendizagem e apontam para os projetos como uma peça central da filosofia construtivista na sala de aula (Hernández, 1998). Afinal:

Aprender a pensar criticamente requer dar significado à informação, analisá-la, sintetizá-la, planejar ações, resolver problemas, criar novos materiais ou ideias, [...] e envolver-se mais na tarefa de aprendizagem. (Bruner, 1919, p. 10 citado em Hernández, 1998, p. 72).

Na década de 90 do século passado esse processo se ampliou e algumas publicações fundamentadas em resultados de pesquisas e de experiências de sucesso fortaleceram ainda mais a ABP. Podem ser citadas a experiência da escola Pompeu de Fabra, descrita por Hernández e Ventura (1998), a relação entre a ABP, a motivação e a tecnologia apresentadas por Blumenfeld et al. (1991), entre outros.

Esse interesse só cresceu desde então, sendo fortalecido pelas constantes inovações tecnológicas e pela compreensão cada vez maior acerca da cognição humana. Também contribuem para o crescente interesse pela ABP o fato de as características esperadas do cidadão do presente século irem ao encontro do que essa metodologia pode oferecer.

Além desses autores cuja importância é sempre lembrada no uso educacional dos projetos, existem outros que tiveram contribuição relevante. Podem ser citados Ovide Decroly, na França, que criou os "Centros de Interesse"; Maria Montessori, na Itália; Celestin Freinet, na França, que protagonizou a Pedagogia de Projetos, entre outros (Oliveira, 2006). Há de se fazer referência também à grande influência dos autores ligados à origem e ao desenvolvimento do construtivismo, uma vez que eles orientaram um grande desenvolvimento na ABP.

Após este breve apanhado histórico sobre as origens da ABP, apresenta-se na sequência a metodologia de pesquisa desta revisão da literatura focada na ABP no contexto do ensino de Física nos últimos dez anos.

\section{Metodologia}

Consistente com as definições e orientações metodológicas de Cooper, Hedges, \& Valentine (2009), foi desenvolvida uma revisão sistemática da literatura que considerou, em particular, os estágios de definição do problema, busca na literatura, avaliação dos dados, análise dos dados, interpretação dos resultados e apresentação pública. Esta revisão compreende publicações entre 2005 e 2015 de revistas especializadas, nacionais e estrangeiras, da área de ensino. A seleção dos artigos foi realizada em quatro etapas, descritas a seguir.

Etapa 1: busca na plataforma ERIC (Education Resources Information Center) 
e nos periódicos classificados nas categorias A1, A2 e B1 no Qualis 2014 da Área 46 - Ensino, da CAPES e em revistas consideradas relevantes para a área usando a ferramenta de pesquisa avançada da plataforma Google Acadêmico, para cada periódico individualmente. Nesta etapa foram usados os seguintes descritores em inglês, em todos os casos, e adicionalmente em português e espanhol para aquelas revistas que publicam nessas línguas: em Inglês: ("Project-Based Learning" OR "Project Based Learning" OR "PBL" OR "Project Method" OR "Pedagogy of Projects") AND "Physics"; em Português: ("Metodologia de projetos" OR "Método de projetos" OR "Pedagogia de Projetos" OR "Aprendizagem Baseada em Projetos" OR "ABP" OR "ABProj" OR "Ensino por projetos") AND "Física"; e em Espanhol: ("Método de Proyectos" OR "Aprendizaje por Proyectos" OR "Aprendizaje Basado en Proyectos" OR "ABP” OR "Pedagogía en base a proyectos") AND "Física". A Figura 2 apresenta a relação de todas as revistas e banco de dados consultados, que resultou na seleção de 263 artigos.

Etapa 2: leitura do resumo (abstract) de todos os artigos selecionados na primeira etapa, bem como dos trechos contendo os descritores usados na busca, a fim de avaliar o alinhamento do artigo com os objetivos desta revisão. Foram mantidos os artigos que versam sobre ABP aplicada ao ensino de Física, aqueles que apresentavam metodologia semelhante à $\mathrm{ABP}^{1}$, bem como aqueles que tratam visceralmente da $\mathrm{ABP}$, i.e., têm como objetivo discutir teoricamente características da ABP sem o direcionamento a uma disciplina específica. Foram excluídos os artigos que só citam a ABP sem tratar efetivamente do tema, os que tratam da ABP no contexto de outras disciplinas sem incluir temas de Física e os que tratam da Aprendizagem Baseada em Problemas (PBL).

Após essa etapa da seleção, foram excluídos 199 artigos, sendo 72 por serem artigos com mais de 10 anos desde a sua publicação original e que foram apenas disponibilizados eletronicamente no período de busca ${ }^{2} ; 76$ artigos por não tratarem de Ensino de Física; 65, por só citarem a $\mathrm{ABP}$ e 16 por tratarem de outra metodologia como o Problem-Based Learning $(\mathrm{PBL})^{3}$. Cabe observar que alguns artigos foram excluídos por mais de um desses motivos. Restaram 64 artigos que tratam da Aprendizagem Baseada em Projetos no contexto do Ensino de Física.

Etapa 3: leitura integral dos 64 artigos selecionados e nova avaliação individual seguindo os mesmos critérios de exclusão da etapa dois, resultando na manutenção de 38 artigos. Foram acrescentados outros três, devido ao grande número de citações e/ou ao alinhamento com esta revisão: Blumenfeld et al. (1991); Helle, Tynjälä, e Olkinuora (2006); Thomas (2000). Também pelo alinhamento com as questões de pesquisa foram considerados cinco livros que versam sobre a ABP: Bender (2014); Hernández (1998); Hernández e Ventura (1998); Markham, Larmer, e Ravitz (2008); Moura e Barbosa, 1 Entre os achados iniciais foram encontrados 10 artigos com metodologias semelhantes à ABP apesar de adotarem denominações diferentes tais como Project-Based Science e Design-Based Science. Esses artigos foram mantidos para a etapa 3, na qual ocorreu uma análise mais profunda dos textos.

2 A disponibilização eletrônica no período de busca fez com que o Google Acadêmico selecionasse artigos publicados fora do período de interesse.

3 O Problem-Based Learning também explora a resolução de um problema, mas não prevê a criação de artefatos nem a execução de um projeto. 
(2013). Sendo assim, esta revisão conta com 41 artigos que tratam da ABP no contexto do Ensino de Física e cinco livros sobre a ABP.

\begin{tabular}{|c|c|c|}
\hline Classificação & Título & Idioma das Publicações \\
\hline \multirow{8}{*}{$\mathrm{A} 1$} & Ciência \& Educação & Inglês, Português e Espanhol \\
\hline & $\begin{array}{l}\text { Revista Ensaio: Avaliação e Políticas Públicas em } \\
\text { Educação }\end{array}$ & Inglês, Português e Espanhol \\
\hline & International Journal of Science Education & Inglês \\
\hline & Physics Education & Inglês \\
\hline & Revista Brasileira de Ensino de Física & Inglês, Português e Espanhol \\
\hline & Journal of Science Education & Inglês \\
\hline & Science \& Education & Inglês \\
\hline & Teaching and Teacher Education & Inglês \\
\hline \multirow{6}{*}{ A2 } & Ensaio: Pesquisa em Educação em Ciências & Inglês, Português e Espanhol \\
\hline & Investigações em Ensino de Ciências & Inglês, Português e Espanhol \\
\hline & Revista Electrónica de Enseñanza de las Ciencias & Inglês, Português e Espanhol \\
\hline & Revista Brasileira de Estudos Pedagógicos & Inglês, Português e Espanhol \\
\hline & $\begin{array}{l}\text { Revista Brasileira de Pesquisa em Educação em } \\
\text { Ciências }\end{array}$ & Inglês, Português e Espanhol \\
\hline & $\begin{array}{l}\text { Revista Electrónica de Investigación em Educación } \\
\text { em Ciencias }\end{array}$ & Inglês, Português e Espanhol \\
\hline \multirow{8}{*}{ B1 } & Acta Scientiae & Inglês, Português e Espanhol \\
\hline & Alexandria & Inglês, Português e Espanhol \\
\hline & Caderno Brasileiro de Ensino de Física & Inglês, Português e Espanhol \\
\hline & Experiências em Ensino de Ciências & Inglês, Português e Espanhol \\
\hline & Latin - American Journal of Physics Education & Inglês, Português e Espanhol \\
\hline & $\begin{array}{l}\text { Revista Brasileira de Ensino de Ciências e } \\
\text { Tecnologia }\end{array}$ & Inglês, Português e Espanhol \\
\hline & Revista de Enseñanza de la Física & Inglês, Português e Espanhol \\
\hline & Science Education International & Inglês \\
\hline \multirow{8}{*}{$\begin{array}{l}\text { Periódicos não } \\
\text { classificados no } \\
\text { Qualis } 2014 \text { na } \\
\text { área de Ensino }\end{array}$} & American Journal of Physics & Inglês \\
\hline & Cognition Instruction & Inglês \\
\hline & Computers \& Education & Inglês \\
\hline & Enseñanza de las Ciências & Inglês, Português e Espanhol \\
\hline & Journal of Computer Assisted Learning & Inglês \\
\hline & Journal of Research in Science Teaching & Inglês \\
\hline & Research in Science Education & Inglês \\
\hline & Science Education & Inglês \\
\hline Banco de Dados & ERIC & Inglês \\
\hline
\end{tabular}

Figura 2. Lista de periódicos e bancos de dados (BD) consultados, e idioma(s) usado(s) na pesquisa. 


\section{Qual o perfil da produção acadêmica a respeito da ABP no contexto do Ensino de Física?}

A fim de traçar o perfil da produção acadêmica sobre a ABP são apresentadas as classificações dos artigos selecionados quanto à sua natureza, nível de ensino a que se destinam e denominação atribuída ao uso educacional dos projetos.

Natureza dos trabalhos: Os artigos foram classificados em: a) pesquisa (contém questões de pesquisa, metodologia de pesquisa, análise de dados e resultados baseados nos dados); b) relato de experiência (apresentam propostas implementadas sem as características de uma pesquisa); c) artigo de reflexão (o foco está na reflexão teórica sobre o tema); d) apresentação de proposta (contém propostas sem implementação) e e) revisão da literatura (apresentam escopo, questões de pesquisa e discussão baseada nos artigos do escopo). Os resultados desta classificação são apresentados na Figura 3 juntamente com a classificação quanto ao nível de ensino.

Nível de ensino: Os artigos foram agrupados nas seguintes categorias: Ensino Fundamental (E.F.), Ensino Médio (E.M.), Ensino Superior (E.S.) e Pós-Graduação (P.G.). Os resultados desta classificação são apresentados no Figura 3, onde se pode verificar a predominância de artigos que versam sobre o Ensino Fundamental e o Ensino Superior. Particularmente, observa-se carência de trabalhos de pesquisa no nível de Ensino Médio.

Denominação do uso educacional de projetos: Foi possível perceber uma grande variedade na forma de nomear o uso educacional dos projetos, havendo pelo menos 10 denominações ${ }^{4}$ associadas a este uso. Essas denominações foram agrupadas em oito categorias, apresentadas na Figura 4 juntamente com uma breve descrição de cada uma.

\begin{tabular}{|c|c|c|c|}
\hline Natureza & Nível de Ensino & Quant. & Artigos \\
\hline \multirow[t]{3}{*}{ Pesquisa } & Ensino Fundamental & 11 & $\begin{array}{l}\text { Barcelos, Jacobucci, \& Jacobucci, (2010); Basu } \\
\text { (2008); Chue; Lee (2013); Cole,Wilhelm, \& Yang } \\
\text { (2015); Hsu, Van Dyke, Chen, \& Smith (2015); } \\
\text { Kanter (2010); Rivet; Krajcik (2008); Rosenfeld; } \\
\text { Rosenfeld (2006); Schneider, Krajcik, \& Blumenfeld } \\
\text { (2005); Schnittka; Bell (2011); Venville,Sheffield, } \\
\text { Rennie, \& Wallace (2008) }\end{array}$ \\
\hline & Ensino Médio & 2 & Bargerhuff (2013); Batista, Lavaqui, \& Salvi (2008) \\
\hline & Ensino Superior & 6 & $\begin{array}{l}\text { Chang, Wu, Kuo, \& You (2012); Hazari, Tai, \& Sadler } \\
\text { (2007); Machado; Queiroz (2012); Marino, Carreri, } \\
\text { \& Alzugaray (2006); Parisoto, Moreira, \& Dröse } \\
\text { (2014); Shemwell, Avargil, \& Capps (2015) }\end{array}$ \\
\hline
\end{tabular}

Figura 3. Classificação dos artigos quanto à sua natureza e nível de ensino (continua)

4 São consideradas aqui somente as denominações mais relevantes em cada artigo. O agrupamento se deu conforme livre tradução dos autores do presente artigo para a língua portuguesa. 


\begin{tabular}{|c|c|c|c|}
\hline Natureza & Nível de Ensino & Quant. & Artigos \\
\hline \multirow{4}{*}{$\begin{array}{l}\text { Relato de } \\
\text { Experiência }\end{array}$} & Ensino Fundamental & 2 & $\begin{array}{l}\text { Langbeheim (2015); Weizman, Shwartz, \& } \\
\text { Fortus (2008) }\end{array}$ \\
\hline & Ensino Médio & 2 & $\begin{array}{l}\text { Espíndola; Moreira (2006); Ezquerra, Manso, } \\
\text { Burgos, \& Hallabrin (2014) }\end{array}$ \\
\hline & Ensino Superior & 8 & $\begin{array}{l}\text { Baldock; Chanson (2006); Chang, Chen, } \\
\text { Kuo, \& Shen (2011); Espín et al. (2015); Jou, } \\
\text { Chuang, \& Wu (2010); Morales (2009); Raposo } \\
\text { (2014); Silva, Brizolla, \& Da Silva (2013); } \\
\text { Tuyarot; Arriassecq (2015) }\end{array}$ \\
\hline & Pós-Graduação & 1 & Sanders, Faesi, \& Goodman (2013) \\
\hline \multirow[t]{2}{*}{$\begin{array}{l}\text { Artigo de } \\
\text { Reflexão }\end{array}$} & $\begin{array}{l}\text { Ensino Fundamental, } \\
\text { Ensino Médio e } \\
\text { Ensino Superior }\end{array}$ & 4 & $\begin{array}{l}\text { Blumenfeld et al. (1991); Meltzer; Otero } \\
\text { (2015); Quintana-Nedelcos; Llovera-González } \\
\text { (2009); Zômpero; Laburú (2011) }\end{array}$ \\
\hline & Ensino Médio & 1 & Lavaqui \& Batista (2007) \\
\hline \multirow[t]{2}{*}{$\begin{array}{l}\text { Revisão da } \\
\text { Literatura }\end{array}$} & $\begin{array}{l}\text { Ensino Fundamental, } \\
\text { Ensino Médio e } \\
\text { Ensino Superior }\end{array}$ & 2 & $\begin{array}{l}\text { Thomas (2000); Yanitelli, Scancich, \& Pala } \\
\text { (2015) }\end{array}$ \\
\hline & Ensino Superior & 1 & Helle, Tynjälä, \& Olkinuora (2006) \\
\hline $\begin{array}{l}\text { Apresentação } \\
\text { de Proposta }\end{array}$ & Ensino Médio & 1 & Ivanov, Nikolov, \& Petrova (2014) \\
\hline
\end{tabular}

Figura 3. Classificação dos artigos quanto à sua natureza e nível de ensino

\begin{tabular}{|c|c|c|c|}
\hline Denominação & $\begin{array}{l}\text { Breve Descrição da } \\
\text { Metodologia }\end{array}$ & Quant. & Artigos \\
\hline $\begin{array}{l}\text { Aprendizagem } \\
\text { Baseada em } \\
\text { Projetos (ABP) } \\
\text { (Project-Based } \\
\text { Learning) }\end{array}$ & $\begin{array}{l}\text { Investigação ancorada em } \\
\text { dois elementos centrais: a } \\
\text { exploração de uma questão } \\
\text { norteadora que organiza } \\
\text { e orienta a investigação e } \\
\text { a construção de artefatos } \\
\text { relacionados à questão motriz } \\
\text { (Langbeheim, 2015) }\end{array}$ & 22 & $\begin{array}{l}\text { Baldock; Chanson (2006); Bargerhuff } \\
\text { (2013); Basu (2008); Blumenfeld et } \\
\text { al. (1991); Chang, Chen, Kuo, \& Shen } \\
\text { (2011); Chang, Wu, Kuo, \& You (2012); } \\
\text { Cole, Wilhelm, \& Yang (2015); Espín } \\
\text { et al. (2015); Ezquerra, Manso, Burgos, } \\
\text { \& Hallabrin (2014); Helle, Tynjälä, } \\
\text { \& Olkinuora (2006); Hsu, Van Dyke, } \\
\text { Chen, \& Smith (2015); Ivanov, Nikolov, } \\
\text { \& Petrova (2014); Jou, Chuang, \& Wu } \\
\text { (2010); Langbeheim (2015); Morales } \\
\text { (2009); Quintana-Nedelcos; Llovera- } \\
\text { González (2009); Rosenfeld; Rosenfeld } \\
\text { (2006); Sanders, Faesi, \& Goodman } \\
\text { (2014); Shemwell, Avargil, \& Capps } \\
\text { (2015); Thomas (2000); Venville, } \\
\text { Sheffield, Rennie, \& Wallace (2008); } \\
\text { Yanitelli, Scancich, \& Pala (2015) }\end{array}$ \\
\hline
\end{tabular}

Figura 4. Denominações usadas no trabalho educacional com projetos (continua) 


\begin{tabular}{|c|c|c|c|}
\hline Denominação & Breve Descrição da Metodologia & Quant. & Artigos \\
\hline $\begin{array}{l}\text { Ciências Baseada } \\
\text { em Design } \\
\text { (DBS) } \\
\text { (Design-Based } \\
\text { Science) }\end{array}$ & $\begin{array}{l}\text { Utiliza a concepção de artefatos para construir } \\
\text { novas habilidades de conhecimentos científicos } \\
\text { e de resolução de problemas. (Fortus, Krajcik, } \\
\text { Dershimer, Marx, \& Mamlok-Naaman, 2005, p. } \\
\text { 855). }\end{array}$ & 1 & $\begin{array}{l}\text { Schnittka \& Bell } \\
(2011)\end{array}$ \\
\hline $\begin{array}{l}\text { Ciências Baseada } \\
\text { em Design (DBS) } \\
\text { (Design-Based } \\
\text { Science) }\end{array}$ & $\begin{array}{l}\text { Utiliza a concepção de artefatos para construir } \\
\text { novas habilidades de conhecimentos científicos } \\
\text { e de resolução de problemas. (Fortus, Krajcik, } \\
\text { Dershimer, Marx, \& Mamlok-Naaman, 2005, p. } \\
\text { 855). }\end{array}$ & 1 & $\begin{array}{l}\text { Schnittka \& Bell } \\
(2011)\end{array}$ \\
\hline $\begin{array}{l}\text { Ciências Baseada } \\
\text { em Projetos (PBS) } \\
\text { (Project-Based } \\
\text { Science) } \\
\\
\end{array}$ & $\begin{array}{l}\text { Busca envolver os alunos em uma extensiva } \\
\text { investigação científica dirigida por eles mesmos e } \\
\text { apoiada pelo uso de tecnologia e por colaborações } \\
\text { externas. De forma geral, é possível caracterizar } \\
\text { o PBS por cinco características gerais: questão } \\
\text { motriz, criação de artefato, investigação } \\
\text { científica, trabalho colaborativo e tecnologias de } \\
\text { aprendizagem. (Schneider, Krajcik, \& Blumenfeld, } \\
\text { 2005, p. 288). }\end{array}$ & 5 & $\begin{array}{l}\text { Hazari, Tai, \& Sadler } \\
\text { (2007); Kanter } \\
\text { (2010); Rivet; } \\
\text { Krajcik (2008); } \\
\text { Schneider, Krajcik, \& } \\
\text { Blumenfeld (2005); } \\
\text { Weizman, Shwartz, \& } \\
\text { Fortus (2008) }\end{array}$ \\
\hline $\begin{array}{l}\text { Ensino / } \\
\text { Aprendizagem } \\
\text { por Projetos } \\
\text { (Enseñanza por } \\
\text { Proyectos) }\end{array}$ & $\begin{array}{l}\text { Costumam envolver a definição de um assunto } \\
\text { para investigação, planejamento das etapas do } \\
\text { projeto, execução de tarefas com a mediação } \\
\text { de um docente, apresentação de resultados aos } \\
\text { colegas e/ou comunidade, registros das atividades } \\
\text { desenvolvidas e momentos de avaliação. }\end{array}$ & 5 & $\begin{array}{l}\text { Silva, Brizolla, \& Da } \\
\text { Silva (2013); Tuyarot; } \\
\text { Arriassecq (2015); } \\
\text { Zômpero; Laburú } \\
\text { (2011) }\end{array}$ \\
\hline $\begin{array}{l}\text { Investigação } \\
\text { Baseada em } \\
\text { Design (DBI) } \\
\text { (Design-Based } \\
\text { Inquiry) } \\
\end{array}$ & $\begin{array}{l}\text { Desafia os alunos a projetar ou revisar artefatos } \\
\text { de forma interativa, com o objetivo de criar um } \\
\text { ambiente motivador para a aprendizagem de } \\
\text { conceitos científicos. (Chue \& Lee, 2013) }\end{array}$ & 1 & Chue \& Lee (2013) \\
\hline $\begin{array}{l}\text { Metodologia } \\
\text { ou Método de } \\
\text { Projetos (Project } \\
\text { Method) }\end{array}$ & $\begin{array}{l}\text { "[...] prevê "a sistematização de atividades e } \\
\text { recursos realizadas com o objetivo de alcançar } \\
\text { alguma produção, por exemplo resolver questões } \\
\text { problemáticas, obter bens ou prestar serviços que } \\
\text { satisfaçam alguma necessidade" (Marino, Carreri, } \\
\text { \& Alzugaray, 2006, p. 50). }\end{array}$ & 3 & $\begin{array}{l}\text { Marino, Carreri, \& } \\
\text { Alzugaray (2006); } \\
\text { Meltzer; Otero } \\
\text { (2015); Parisoto, } \\
\text { Moreira, \& Dröse } \\
\text { (2014) }\end{array}$ \\
\hline $\begin{array}{l}\text { Pedagogia de } \\
\text { Projetos (Project- } \\
\text { Based Pedagogy) }\end{array}$ & $\begin{array}{l}\text { Usa temas geradores como ponto de partida a fim } \\
\text { de guiar o estudo posterior (Raposo, 2014, p. 725). } \\
\text { Não prevê um método fixo, mas baseia-se em uma } \\
\text { série de condições que devem ser respeitadas. } \\
\text { (Hernandez, } 2008 \text { citado em Raposo, 2014, p. } \\
\text { 725). }\end{array}$ & 5 & $\begin{array}{l}\text { Espíndola; Moreira } \\
\text { (2006); Lavaqui; } \\
\text { Batista (2007); } \\
\text { Machado; Queiroz } \\
\text { (2012); Quintana- } \\
\text { Nedelcos; Llovera- } \\
\text { González (2009); } \\
\text { Raposo (2014) }\end{array}$ \\
\hline
\end{tabular}

Figura 4. Denominações usadas no trabalho educacional com projetos (continua) 


\begin{tabular}{|c|c|c|c|}
\hline Denominação & Breve Descrição da Metodologia & Quant. & Artigos \\
\hline $\begin{array}{l}\text { Trabalho por } \\
\text { Projetos }\end{array}$ & $\begin{array}{l}\text { Aborda projetos interdisciplinares em sala de aula* a } \\
\text { partir de: escolha de um tema; identificação do que } \\
\text { se sabe sobre o assunto; determinação das questões } \\
\text { centrais; definição de estratégias de trabalho; } \\
\text { desenvolvimento das estratégias; sistematização } \\
\text { e apresentação e divulgação e avaliação. (Batista, } \\
\text { Lavaqui, \& Salvi, 2008, p. 219) }\end{array}$ & 1 & $\begin{array}{l}\text { Batista, Lavaqui, \& } \\
\text { Salvi (2008) }\end{array}$ \\
\hline
\end{tabular}

Figura 4. Denominações usadas no trabalho educacional com projetos

Nota: ${ }^{\star}$ Outras etapas, ligadas ao planejamento do docente, tais como ordenação de conteúdo, análise diagnóstica, planejamento anual das disciplinas e avaliação do trabalho desenvolvido também são previstas na metodologia.

A descrição das ações e características encontradas nos artigos elencados nesta revisão, e resumidas no Figura 4, apontou muito mais semelhanças do que diferenças entre os procedimentos atribuídos às diferentes denominações. Percebeu-se também que a nomenclatura empregada não reflete, necessariamente, uma diferença metodológica. Por vezes, uma mesma denominação apresenta diferentes acepções e, em outros casos, o uso pedagógico dos projetos foi nomeado de mais de uma forma em um mesmo artigo, por exemplo em Quintana-Nedelcos \& Llovera-González (2009) e Barcelos, Jacobucci, \& Jacobucci (2010).

Os textos parecem se referir a um universo mais amplo do que um método didático específico. Tal afirmação se fundamenta não só na variedade de denominações encontradas, como também na ausência de distinção explícita entre as nomenclaturas citadas. Apesar disso, não é possível afirmar que não existem diferentes métodos de uso dos projetos, e sim, que a literatura consultada não ressalta tais diferenças. A literatura pesquisada parece se direcionar a uma abordagem didática, flexível o suficiente para permitir variações que não a descaracterizam.

De forma geral, as propostas de uso educacional dos projetos se fundamentam em algumas características comuns: o desenvolvimento dos projetos a partir de um tema ou questão norteadora, o desenvolvimento de um artefato, o trabalho colaborativo e o protagonismo dos estudantes.

Frente a isso, sem negar que possam existir diferentes metodologias de projetos (apesar de não explícitos nos artigos pesquisados) e com o objetivo de assumir uma expressão única, foi adotada neste trabalho a denominação Aprendizagem Baseada em Projetos (ABP). Essa escolha se justifica não só por ter sido a nomenclatura mais usada nos artigos, mas principalmente por, na visão dos autores desta revisão, refletir melhor a flexibilidade e a amplitude potencial do uso educacional dos projetos.

Portanto, considerando os resultados compilados nas Figuras 3 e 4, podemos caracterizar a produção acadêmica investigada como constituída de trabalhos de Pesquisa (19), Relatos de Experiência (13), Artigo de Reflexão (5), Revisão da Literatura (3) e Apresentação de Proposta (1). Quanto ao nível de ensino, os trabalhos se realizaram em: Ensino Superior (15), Ensino Fundamental (13), Ensino Médio (6), Pós-Graduação 
(1) e Multinível $^{5}$ (6). Foi identificada, ainda, uma considerável variedade nas formas de nomear o uso educacional dos projetos sem que fosse possível definir claramente distinções entre elas.

\section{Quais as principais concepções e orientações metodológicas acerca da ABP?}

Quanto às concepções e orientações metodológicas acerca da ABP, diversos são os autores citados como referências, existindo predominância de um grupo de pesquisadores da Universidade de Michigan, aqui nomeado de grupo PBS 6 . Destacamse também Thomas (2000), Fernando Hernández (Hernández, 1998; Hernández \& Ventura, 1998), Barron et al. (1998), Prado (2003) e Macías-Guarasa, Montero, SanSegundo, Araujo, \& Nieto-Taladriz (2006). A Figura 5 organiza os artigos conforme o(s) autor(es) citado(s).

\begin{tabular}{|c|c|c|}
\hline Autor ou Grupo* & Quant. & Referências \\
\hline Grupo PBS & 12 & $\begin{array}{l}\text { Baldock; Chanson (2006); Hazari, Tai, \& Sadler (2007); Hsu, P.- } \\
\text { S., Van Dyke, Chen, \& Smith (2015); Jou, Chuang, \& Wu (2010); } \\
\text { Kanter (2010); Langbeheim (2015); Rivet; Krajcik (2008); Rosenfeld; } \\
\text { Rosenfeld (2006); Sanders, Faesi, \& Goodman (2014); Schneider, } \\
\text { Krajcik, \& Blumenfeld (2005); Shemwell, Avargil, \& Capps (2015); } \\
\text { Weizman, Shwartz, \& Fortus (2008) }\end{array}$ \\
\hline J. W. Thomas & 6 & $\begin{array}{l}\text { Chang, Chen, Kuo, \& Shen (2011); Ezquerra, Manso, Burgos, \& } \\
\text { Hallabrin (2014); Jou, Chuang, \& Wu (2010); Morales (2009); } \\
\text { Sanders, Faesi, \& Goodman (2013); Shemwell, Avargil, \& Capps } \\
\text { (2015) }\end{array}$ \\
\hline B. Barron et al. & 5 & $\begin{array}{l}\text { Chue; Lee (2013); Hazari, Tai, \& Sadler (2007); Helle, Tynjälä, \& } \\
\text { Olkinuora (2006); Kanter (2010); Thomas (2000) }\end{array}$ \\
\hline F. Hernandez & 4 & $\begin{array}{l}\text { Barcelos, Jacobucci, \& Jacobucci (2010); Espíndola; Moreira (2006); } \\
\text { Machado; Queiroz (2012); Raposo (2014) }\end{array}$ \\
\hline M.E.B.B. Prado & 2 & Machado; Queiroz (2012); Raposo (2014) \\
\hline $\begin{array}{l}\text { J. Macías-Guarasa } \\
\text { et al. }\end{array}$ & 2 & Chang, Chen, Kuo, \& Shen (2011) ; Chang, Wu, Kuo, \& You (2012) \\
\hline Não Consta & 8 & $\begin{array}{l}\text { Bargerhuff (2013); Basu (2008); Ivanov, Nikolov, \& Petrova (2014); } \\
\text { Marino, Carreri, \& Alzugaray (2006); Silva, Brizolla, \& Da Silva } \\
\text { (2013); Venville, Sheffield, Rennie, \& Wallace (2008); Yanitelli, } \\
\text { Scancich, \& Pala (2015); Zômpero; Laburú (2011) }\end{array}$ \\
\hline
\end{tabular}

Figura 5. Artigos organizados conforme as concepções e orientações metodológicas citadas ${ }^{7}$. Nota: *Foram incluídos autores ou grupo de autores citados ao menos em dois artigos.

Os textos dos autores citados não necessariamente se propõem a ser um referencial metodológico de ensino para a ABP e sua análise aponta distinções e semelhanças nas

5 Foram classificados como multinível os artigos que tratavam concomitantemente de mais de um nível de ensino. 6 O Grupo PBS é formado fundamentalmente pelos seguintes autores: P. C Blumenfeld; J. Krajcik; A. Rivet; R. M. Schneider; R. W. Marx; E. Soloway; R. W Marx.

7 Um artigo pode ter citado mais de um autor. 
concepções e/ou orientações metodológicas apresentadas por cada autor. A fim de oferecer um breve panorama apresenta-se a seguir as ideias principais de cada um.

O Grupo PBS, composto por pesquisadores ligados à Universidade de Michigan, desenvolve e investiga a ABP e propõe a Ciência Baseada em Projetos (PBS) sem, no entanto, restringir-se a ela. As iniciativas PBS buscam problematizar a ciência através de situações significativas para os estudantes e que exigem o conhecimento de determinados conceitos científicos. A partir dessa situação, os estudantes trabalham colaborativamente, por um longo período, em investigações guiadas por uma questão motriz, que conduz à produção de artefatos, ou seja, de "representações de soluções da questão motriz que refletem estados emergentes do conhecimento" (Blumenfeld et al., 1991, p.371). Os artefatos são avaliados e melhorados ao longo do processo.

Thomas (2000) apresenta uma revisão da literatura em que examina investigações sobre a ABP ao longo da década de 1990 discutindo temas como a definição da ABP, a sua eficácia, as características e o papel dos estudantes na $\mathrm{ABP}$, os resultados das pesquisas no período e aponta direções para futuras investigações. Este autor também apresenta cinco critérios que assinalam o que uma proposta $\mathrm{ABP}$ deve conter:

Centralidade: se refere à necessidade de que os projetos sejam a estratégia central de ensino, ou seja, é através deles que os estudantes devem aprender os conceitos centrais da disciplina;

Questão motriz: foco em questões ou problemas que movem os alunos ao encontro dos princípios e conceitos centrais de uma disciplina;

Investigações Construtivas: envolvem transformação e construção do conhecimento, i.e., desenvolvem novos entendimentos e novas habilidades;

Autonomia: liberdade para que os estudantes determinem o caminho da sua investigação;

Realismo: requer a incorporação de problemas da vida real e de soluções com potencial de ser implementadas.

Barron et al. (1998) apresentam uma abordagem para a concepção, implementação e avaliação de currículo baseado em problemas e em projetos. Eles fundamentam sua proposta em quatro princípios de design:

Metas de aprendizagem apropriadas: contextualização e questões motrizes que conduzam os estudantes a executar o projeto com compreensão do conhecimento conceitual subjacente;

Apoio instrucional: processos como aprendizagem baseada em problemas ou o uso de casos contrastantes que permitam a professores e estudantes realizar tarefas que não seriam possíveis sem esse apoio. 
Oportunidades frequentes para a auto avaliação formativa e revisão: etapas em que os projetos recebem feedback e são avaliados pelos próprios estudantes com a oportunidade de revisá-los e melhorá-los;

Desenvolvimento de estruturas sociais que promovam a participação e o senso de agência: estratégias desenvolvidas a partir de mecanismos sociais que visam transformar o estudante de um receptor passivo a um aprendiz ativo e reflexivo, i.e., dotado do que Barron et al. (1998, p. 285) chamam de senso de agência. Entre as maneiras de apoiar essa aprendizagem ativa pode-se citar trabalho colaborativo, interação com os pares, apresentações externas à sala de aula, entre outras.

Fernando Hernandez é o autor com abordagem mais holística entre os citados. Sua visão dos projetos vai muito além da práxis da sala de aula, permeando a organização curricular e outras dimensões da escola. Ele propõe que os projetos partam da definição de um tema originado na demanda dos estudantes, desde que eles sejam capazes de argumentar sobre a relevância do assunto. Nesse sentido, Hernandez parece ser mais flexível do que Thomas (2000), já que admite que o tema do projeto advenha de outras fontes que não o currículo oficial (Hernández \& Ventura, 1998). Essa postura tem relação direta com sua visão de projetos. "Segundo Hernandez (1998), os projetos não podem ser considerados como modelos pedagógicos prontos e acabados, ou como metodologia didática para o cumprimento do currículo, separados de sua dimensão política" (Machado \& Queiroz, 2012, p. 96).

Hernández, assim como os demais autores, se opõe ao estabelecimento de uma sequência rígida e estável de passos a ser seguida no desenvolvimento dos projetos. Apesar de sugerir possíveis tarefas para alunos e professores (Hernández \& Ventura, 1998) e apontar algumas condições a serem respeitadas, (Hernandez, 2008 citado em Raposo, 2014), Hernández destaca a importância de que o desenvolvimento do projeto considere a realidade e as circunstâncias de sua aplicação.

As ideias de Maria Prado vão ao encontro da visão de Hernandez no que se refere à busca de um método para desenvolver projetos: “[...] não existe um modelo ideal pronto e acabado que dê conta da complexidade que envolve a realidade de sala de aula, do contexto escolar" (Prado, 2003, p. 6); “[...] no trabalho por projetos, as pessoas se envolvem para descobrir ou produzir algo novo, procurando respostas a questões ou problemas reais" (Prado, 2003, p. 8). Há, portanto, uma discordância em relação ao uso do projeto como exercício (Helle, Tynjälä, \& Olkinuora, 2006) e concordância com o critério de que os projetos devem envolver investigações construtivas (Thomas, 2000) afinal, “[...] quando se conhece a priori todos os passos para solucionar o problema, esse processo se constitui num exercício e aplicação do que já se sabe” (Almeida, 2002, citado em Prado, 2003, p.6).

Para Prado (2003), o papel do professor é o de mediador, ou seja, o de ouvir, questionar e orientar a fim de criar situações de aprendizagem que levem o aluno a formalizar os conceitos colocados em ação. Ela destaca o potencial interdisciplinar dos projetos e defende que a interdisciplinaridade não nega a prática disciplinar, pelo 
contrário, "[...]ela se dá sem que haja perda da identidade das disciplinas"(Fazenda, 1994 citado em Prado, 2003, p.8). De forma resumida:

A pedagogia de projetos deve permitir que o aluno APRENDA-FAZENDO e reconheça a própria AUTORIA naquilo que produz por meio de QUESTÕES DE INVESTIGAÇÃO que lhe impulsionam a CONTEXTUALIZAR CONCEITOS já conhecidos e DESCOBRIR outros que emergem durante o desenvolvimento do projeto. Nesta situação de aprendizagem, o aluno precisa selecionar informações significativas, tomar decisões, trabalhar em grupo, gerenciar confronto de idéias, enfim desenvolver COMPETÊNCIAS INTERPESSOAIS para aprender de forma colaborativa com seus pares (Prado, 2003, p. 7, grifos da autora).

Macías-Guarasa, Montero, San-Segundo, Araujo, \& Nieto-Taladriz (2006) apresentam um estudo em que buscam verificar se o interesse dos estudantes por eletrônica aumenta quando participam de cursos fundamentados na ABP. Para tanto, propõem um currículo de Engenharia Eletrônica que integra cursos teóricos e iniciativas de ABP sem impor necessariamente o teórico como pré-requisito. Embora seja um estudo interessante, com bons resultados e com sugestões práticas para a implementação, não parece ser uma fonte de concepções e/ou orientações metodológicas acerca da ABP.

Além dos diversos autores destacados aqui, é possível verificar também que há um considerável número de artigos que não estabelecem um referencial de concepções e orientações metodológicas para a ABP. A título de exemplificação desta categoria pode-se citar Basu (2008). A relação deste artigo com a ABP pôde ser estabelecida pela seguinte afirmação: "Eu planejei o curso com outro professor - nos concentramos em aprendizagem baseada em projetos, avaliação autêntica, e instrução diferenciada"(Basu, 2008, p. 257).

Outro representante desta categoria é Marino, Carreri, \& Alzugaray (2006), que em pesquisa a respeito dos espaços curriculares interdisciplinares envolvendo Física e Biologia, apresentam a ABP como uma metodologia centrada no aluno, com potencial para uma aprendizagem contextualizada e significativa. Vão além, definindo o que chamam de método de projetos sem, no entanto, fundamentar o que definem.

Esses e outros artigos classificados nesta categoria têm como característica o foco principal em temas diversos, ficando a ABP em segundo plano. Por vezes, como no caso de Basu (2008), só há indicação de que a metodologia usada foi a ABP. Entretanto, como discute Thomas (2000) e como esta revisão aponta, não há um modelo universalmente aceito da ABP. Sendo assim, entende-se haver a necessidade de apontar uma referência procedimental ou, ao menos, uma descrição das ações realizadas e nomeadas como relacionadas à de $\mathrm{ABP}$.

Em síntese, a análise dos artigos apontou dispersão quanto aos autores citados como fontes de concepções e orientações metodológicas da ABP. Destacaram-se, entre eles, o Grupo PBS, J. W. Thomas, F. Hernandez, B. J. S. Barron et al., M. Prado e J. Macías-Guarasa, J. M. Montero, R. San-Segundo, Á. Araujo, e Nieto-Taladriz. Embora alguns desses autores não se proponham a ser uma fonte de concepções e/ou orientações 
metodológicas acerca da ABP, os cinco primeiros apresentam contribuições relevantes. Há de se destacar ainda a presença de oito artigos que não explicitam uma referência a respeito de concepções e orientações metodológica sobre a ABP.

\section{Quais os referenciais teóricos de aprendizagem e as metodologias de pesquisa associadas com a ABP?}

\section{Referenciais Teóricos de Aprendizagem}

No intuito de compreender como a literatura tem fundamentado teoricamente o uso da ABP, realizou-se uma análise dos artigos quanto aos referenciais teóricos adotados. Os resultados apontam que uma boa parcela dos artigos (23/41) não apresenta um referencial de aprendizagem, ou simplesmente cita o construtivismo como referencial de maneira muito geral (9/41), sem articulações com as ações realizadas ou mesmo com a ABP. A Figura 6 classifica os artigos de cada categoria.

\begin{tabular}{|l|c|l|}
\hline Referencial de Aprendizagem & Quant. & Artigos \\
\hline Construtivismo & 9 & $\begin{array}{l}\text { Blumenfeld et al. (1991); Chang, Chen, Kuo, \& Shen } \\
\text { (2011); Chang, Wu, Kuo, \& You (2012); Jou, Chuang, } \\
\text { \& Wu (2010); Quintana-Nedelcos; Llovera-González } \\
\text { (2009); Rivet; Krajcik (2008); Rosenfeld; Rosenfeld } \\
\text { (2006); Schnittka; Bell (2011); Thomas (2000) }\end{array}$ \\
\hline $\begin{array}{l}\text { Teoria da Aprendizagem Significativa } \\
\text { (D. P. Ausubel) }\end{array}$ & 4 & $\begin{array}{l}\text { Espíndola; Moreira (2006); Kanter (2010); Morales } \\
\text { (2009); Parisoto, Moreira, \& Dröse (2014) }\end{array}$ \\
\hline $\begin{array}{l}\text { Teoria Sociointeracionista (L. S. } \\
\text { Vygotsky) }\end{array}$ & 3 & $\begin{array}{l}\text { Baldock; Chanson (2006); Espíndola; Moreira (2006); } \\
\text { Morales (2009) }\end{array}$ \\
\hline Teoria Psicogenética (J. W. F. Piaget) & 2 & Baldock; Chanson (2006); Morales (2009) \\
\hline $\begin{array}{l}\text { Pedagogia Libertadora (P. R. N. } \\
\text { Freire) }\end{array}$ & 1 & Espíndola; Moreira (2006); Raposo (2014) \\
\hline $\begin{array}{l}\text { Aprendizagem por Descoberta } \\
\text { (J. S. Bruner) }\end{array}$ & 1 & Morales (2009) \\
\hline $\begin{array}{l}\text { Teoria da Aprendizagem Significativa } \\
\text { Crítica (M. A. Moreira) }\end{array}$ & 1 & Tuyarot \& Arriassecq (2015) \\
\hline $\begin{array}{l}\text { Modelos Mentais (Pirnay-Dummer } \\
\text { et al., 2012) }\end{array}$ & 1 & Cole, Wilhelm, \& Yang (2015) \\
\hline $\begin{array}{l}\text { Teoria da Aprendizagem } \\
\text { Transformadora (J. Mezirow) }\end{array}$ & 1 & Shemwell, Avargil, \& Capps (2015) \\
\hline $\begin{array}{l}\text { Aprendizagem Experiencial } \\
\text { (D. A. Kolb) }\end{array}$ & 1 & Baldock \& Chanson (2006) \\
\hline $\begin{array}{l}\text { Teoria dos Campos Conceituais } \\
\text { (G. Vergnaud) }\end{array}$ & 1 & Parisoto, Moreira, \& Dröse (2014) \\
\hline
\end{tabular}

Figura 6. Referencial de aprendizagem citado em cada artigo desta revisão ${ }^{8}$. (continua)

8 Alguns artigos estão incluídos em mais de uma categoria já que citaram mais de um autor. 


\begin{tabular}{|l|l|l|}
\hline Referencial de Aprendizagem & Quant. & Artigos \\
\hline \multirow{5}{*}{ Não Consta } & & Barcelos et al. (2010); Bargerhuff (2013); Basu \\
& & (2008); Batista et al. (2008); Chue; Lee (2013); \\
& & Espín et al. (2015); Ezquerra et al. (2014); Hazari \\
& & et al. (2007); Hsu et al. (2015); Ivanov et al. (2014); \\
& \multirow{2}{*}{23} & Krajcik et al. (2008); Langbeheim (2015); Lavaqui; \\
& & Batista (2007); Machado; Queiroz (2012); Marino \\
& et al. (2006); Meltzer; Otero (2015); Sanders et al. \\
& (2013); Schneider et al. (2005); Silva et al. (2013); \\
& Venville et al. (2008); Weizman et al. (2008); \\
& Yanitelli et al. (2015); Zômpero; Laburú (2011) \\
\hline
\end{tabular}

Figura 6. Referencial de aprendizagem citado em cada artigo desta revisão

A título de ilustração, apresentam-se a seguir alguns casos que permitem melhor compreensão dos resultados desta seção.

Como exemplo de artigos que apenas citam o construtivismo, temos Jou, Chuang, e Wu (2010) que se limitam a citar que a ABP está de acordo com a abordagem construtivista:

No ambiente de $\mathrm{ABP}$, os alunos constroem seu próprio conhecimento através da aprendizagem ativa, interagindo com o ambiente, tal como sugerido pela abordagem construtivista, e trabalham de forma independente ou colaborando em equipes, enquanto o professor os dirige e os guia na concepção de um produto real (Thomas, 2003, citado em Jou, Chuang, e Wu, 2010, p. 50 ).

Chang, Wu, Kuo, \& You (2012), por sua vez, chegam a citar algumas referências ligadas ao construtivismo, mas não se aprofundam nos conceitos das teorias defendidas pelos autores citados, ou mesmo em como tais abordagens se relacionam com a ABP.

De acordo com as teorias do construtivismo (Honebein, 1996; Wilson, 1996; Tsai, 1998; 2000) e carga cognitiva (Sweller, Van-Merriënboer, e Paas, 1998), os dois estágios de simulação de LED do curso ABP com OPA foram desenvolvidos para melhorar as competências profissionais dos alunos no design do LED, bem como o pensamento meta-cognitivo (Chang, Chen, Kuo, \& Shen, 2011, citado em Chang, Wu, Kuo, \& You, 2012, p. 237).

Outro conjunto de artigos faz referências a autores e teorias específicas no entanto, como no grupo anterior, os autores não apresentam um detalhamento maior a respeito das relações entre a teoria citada e a ABP.

Morales (2009), por exemplo, faz uma relação superficial entre a origem da ABP e diversos autores citados:

As estratégias de instrução baseadas em projetos têm sua origem na aproximação construtivista que evoluiu a partir dos trabalhos de psicólogos e educadores tais como Lev Vygotsky, Jerome Bruner, Jean Piaget e John Dewey [...] (Morales, p. 428).

Além dessa referência múltipla, o autor faz referências específicas a Ausubel, ao dizer que a ABP "pode gerar um ambiente mais indicado para desenvolver uma 
aprendizagem significativa segundo Ausubel" (Morales, p. 428), e a Piaget ao indicar as novas experiências como meio de seguir aprendendo.

Cole, Wilhelm, e Yang (2015) é um dos poucos casos em que se encontra uma articulação coerente, ao longo de todo o texto, a respeito da forma como os estudantes aprendem baseada nos modelos mentais. Os autores partem da ideia de que "os estudantes criam modelos mentais para explicar fenômenos e situações com que se deparam" (Cole, Wilhelm, \& Yang, 2015, p.1816) e que "os estudantes usam esses modelos mentais para interagir com o mundo em torno deles e lhe dar sentido" (p.1817). Sendo assim, as "novas experiências são vistas através das lentes do modelo mental dos estudantes" (Jones, Ross, Lynam, Perez, E Leitch, 2011 citado em Cole, Wilhelm, \& Yang., 2015, p. 1817). A partir dessas premissas, os estudantes foram incentivados a realizar observações e registros diários da Lua com o maior nível de detalhamento possível, bem como a registrar seus questionamentos a respeito do observado. Com isso, os participantes puderam realizar conexões mentais entre as observações feitas e tiveram tempo para transformar seus pensamentos em palavras, condições consideradas fundamentais para explicar os fenômenos observados com base nos dados e na teoria e, assim, atribuir-lhes sentido científico (Cole, Wilhelm, \& Yang, 2015). Essa mesma fundamentação orientou a definição do artefato da proposta, constituído de uma espécie de diário em que as observações, ideias e dúvidas foram registradas:

Neste estudo os alunos utilizaram seus diários de observação da lua, juntamente com os seus modelos mentais como ferramentas para atribuir sentido aos padrões na aparência e localização da Lua ao longo do tempo, mais tarde incorporando um modelo físico tridimensional, para refinar mais a sua compreensão das fases lunares (Cole, Wilhelm, \& Yang, 2015, p. 1817).

\section{Metodologias de Pesquisa}

Em relação às 19 pesquisas empíricas encontradas há um maior número de pesquisas qualitativas (10) em comparação às quantitativas (5) e mistas (4). Os instrumentos de coleta de dados mais utilizados são as notas de campo ou registros de observações (8), entrevistas (8), trabalhos dos estudantes (8), vídeo-filmagens (5), questionários (4) e pré/pós-teste (4). A Figura 7 apresenta um panorama das pesquisas destacando o tipo de pesquisa e os instrumentos utilizados em cada artigo desta natureza.

A partir dos resultados apresentados na Figura 7, percebe-se a ausência de fundamentação teórica de aprendizagem na maioria dos artigos pesquisados e a pouca relevância dada ao tema pelos demais. A ABP é tratada como uma metodologia de ensino de caráter construtivista por uma considerável parcela dos autores. Aqueles que buscam relacionar a ABP a determinadas teorias de aprendizagem, o fazem de maneira superficial e, em sua grande maioria, sem uma efetiva integração com a proposta de ABP apresentada. 


\begin{tabular}{|c|c|c|}
\hline Metodologias & Instrumentos de coleta de dados & Artigos \\
\hline \multirow{10}{*}{ Qualitativa } & Vídeo-filmagens & $\begin{array}{l}\text { Schneider, Krajcik, \& } \\
\text { Blumenfeld (2005) }\end{array}$ \\
\hline & Questionários, notas de campo e entrevistas & $\begin{array}{l}\text { Rosenfeld \& Rosenfeld } \\
\text { (2006) }\end{array}$ \\
\hline & Registros de observação e entrevistas & $\begin{array}{l}\text { Batista, Lavaqui, \& Salvi } \\
\text { (2008) }\end{array}$ \\
\hline & $\begin{array}{l}\text { Notas de campo, registros escolares, análise dos } \\
\text { trabalhos dos estudantes e entrevistas }\end{array}$ & Basu (2008) \\
\hline & $\begin{array}{l}\text { Notas de campo e análise das respostas dos estudantes } \\
\text { a uma questão discursiva }\end{array}$ & $\begin{array}{l}\text { Venville, Sheffield, Rennie, } \\
\text { \& Wallace (2008) }\end{array}$ \\
\hline & Notas de campo e questionário & $\begin{array}{l}\text { Barcelos, Jacobucci, \& } \\
\text { Jacobucci }(2010)\end{array}$ \\
\hline & $\begin{array}{l}\text { Registros redigidos pelos participantes e vídeo- } \\
\text { filmagens }\end{array}$ & $\begin{array}{l}\text { Machado \& Queiroz } \\
(2012)\end{array}$ \\
\hline & $\begin{array}{l}\text { Registros de observação, entrevistas e análise de } \\
\text { documentos escolares }\end{array}$ & Bargerhuff (2013) \\
\hline & $\begin{array}{l}\text { Vídeo-filmagens, entrevistas, notas de observação e } \\
\text { registros escolares }\end{array}$ & Chue \& Lee (2013) \\
\hline & Entrevistas & $\begin{array}{l}\text { Shemwell, Avargil, \& } \\
\text { Capps (2015) }\end{array}$ \\
\hline \multirow{5}{*}{ Quantitativa } & Questionário & $\begin{array}{l}\text { Marino, Carreri, \& } \\
\text { Alzugaray (2006) }\end{array}$ \\
\hline & Questionários & $\begin{array}{l}\text { Hazari, Tai, \& Sadler } \\
\text { (2007) }\end{array}$ \\
\hline & $\begin{array}{l}\text { Pré/Pós-teste, registros de observação, artefatos } \\
\text { criados pelos estudantes e vídeo-filmagens }\end{array}$ & Rivet \& Krajcik (2008) \\
\hline & Pré/Pós-teste & Kanter (2010) \\
\hline & $\begin{array}{l}\text { Teste conceitual de conhecimento das fases da Lua } \\
\text { (Pré/Pós-teste), diários de observação produzidos } \\
\text { pelos estudantes, rubricas de avaliação e entrevistas }\end{array}$ & $\begin{array}{l}\text { Cole, Wilhelm, \& Yang } \\
\text { (2015) }\end{array}$ \\
\hline \multirow{4}{*}{ Mista } & $\begin{array}{l}\text { Registros de observação, entrevistas e artefatos criados } \\
\text { pelos participantes }\end{array}$ & Schnittka \& Bell (2011) \\
\hline & $\begin{array}{l}\text { Mapas Conceituais (Pré/Pós-teste), entrevistas e } \\
\text { avaliação pelos pares }\end{array}$ & $\begin{array}{l}\text { Chang, Wu, Kuo, \& You } \\
(2012)\end{array}$ \\
\hline & $\begin{array}{l}\text { Análise da resolução de questões problema e Mapas } \\
\text { Conceituais }\end{array}$ & $\begin{array}{l}\text { Parisoto, Moreira, \& Dröse } \\
(2014)\end{array}$ \\
\hline & $\begin{array}{l}\text { Vídeo-filmagens, artefatos criados pelos participantes } \\
\text { e rubricas de avaliação }\end{array}$ & $\begin{array}{l}\text { Hsu, Van Dyke, Chen, \& } \\
\text { Smith, (2015) }\end{array}$ \\
\hline
\end{tabular}

Figura 7. Metodologia de pesquisa e instrumentos de coleta de dados das pesquisas.

Nota: *Uma métrica foi utilizada para transformar os dados de instrumentos qualitativos em dados quantitativos. 


\section{Comentários finais}

Neste trabalho foi oferecido um panorama geral da produção acadêmica da $\mathrm{ABP}$ no contexto do Ensino de Física. Para tanto, foram apresentados uma breve revisão histórica da $\mathrm{ABP}$, um perfil da produção acadêmica sobre o tema e um mapeamento da literatura contendo as principais concepções e orientações metodológicas, os referenciais teóricos de aprendizagem e as metodologias de pesquisa presentes nos artigos que envolvem a ABP.

A revisão histórica, ainda que limitada, permitiu elencar possíveis relações entre a trajetória histórica da $\mathrm{ABP}$ e ações ainda presentes nas iniciativas de sua implementação. É importante que aqueles que pretendem implementar ou estudar a ABP tomem conhecimento de sua trajetória histórica a fim de ter clareza de seus princípios e com isso condições de explorar mais amplamente o potencial da metodologia.

O número total de artigos tratando da $\mathrm{ABP}$ (41), e especialmente os que apresentam pesquisas empíricas (19), é pequeno frente ao potencial que a $A B P$ demonstra e ao número de artigos publicados nos periódicos pesquisados. Frente às potencialidades da ABP para a Física no Ensino Médio, chama atenção o baixo número de estudos sobre o tema nesse contexto. Defende-se, portanto, que tanto experiências de implementação quanto estudos empíricos devam ser realizados neste nível a fim de que a $A B P$ não só seja difundida, mas também qualificada.

Outro ponto que se mostrou fértil para aprofundamentos é o da discussão das concepções e orientações metodológicas da $\mathrm{ABP}$ e suas possíveis relações com o desenvolvimento histórico e com as denominações do uso educacional dos projetos. Como relatado por Thomas (2000) e ratificado por esta revisão não há, na literatura, um modelo de ABP universalmente aceito. A mesma diversidade é encontrada nas denominações do uso educacional dos projetos em que parece haver um uso indiscriminado de diferentes termos. $\mathrm{O}$ aprofundamento no tema poderia esclarecer possíveis relações entre os modelos de $\mathrm{ABP}$, denominações do uso dos projetos e o contexto histórico da $\mathrm{ABP}$ e até mesmo definir melhor as fronteiras entre as diferentes concepções de ABP.

O estudo dos referenciais teóricos de aprendizagem apontou que não é dada a devida atenção a essa questão. É preocupante que iniciativas de ensino e aprendizagem sejam levadas a cabo sem a devida reflexão sobre como o estudante aprende. Ainda que as teorias sejam aproximações da realidade e que não sejam completas, elas podem e devem apontar direções e nortear decisões. Portanto, parece razoável que elas permeiem e orientem tanto estudos empíricos quanto iniciativas de implementação. Embora a ABP pareça ser compatível com teorias construtivistas e humanistas, essa flexibilidade não deve ser confundida com a dispensa de uma adequada fundamentação teórica de aprendizagem.

No que se refere às concepções e orientações metodológicas da $\mathrm{ABP}$, foram encontradas variadas referências com predominância das do Grupo PBS e relevantes citações a J. W. Thomas, F. Hernández, B. Barron et al. , M. Prado e J. Macías-Guarasa, 
J. M. Montero, , R. San-Segundo, Á. Araujo, e Nieto-Taladriz. Nesta análise, também foram identificados artigos que não indicam as concepções e orientações metodológicas que fundamentam a proposta. Tal fato pode indicar o desconhecimento da variedade de modelos de ABP, ou mesmo a falta de cuidados procedimentais. Em ambos os casos, as consequências são preocupantes, pois a ausência dessas informações impossibilita a relação entre as ações efetivadas e os resultados obtidos. Aqueles que estudam e/ou implementam a ABP precisam considerar a ausência de um modelo universal desta metodologia, e que isso exige uma descrição mais criteriosa acerca das ações efetuadas.

Certamente o panorama oferecido por esta revisão é limitado e pode ser ampliado através da análise de outros fatores da ABP no contexto do Ensino de Física. Sugere-se, a título de complementação, o estudo de seus elementos básicos, de seus contextos de implementação, dos conteúdos abordados, dos resultados obtidos, do impacto sobre alunos e professores entre outros.

\section{Agradecimentos}

Agradecemos às valiosas observações dos árbitros e da editora, que contribuíram para o aprimoramento deste trabalho. O primeiro e o terceiro autores do trabalho agradecem, respectivamente, ao Instituto Federal de Educação Ciência e Tecnologia do Rio Grande do Sul e ao CNPq pelo suporte parcial recebido.

\section{Referências}

Baldock, T. E., \& Chanson, H. (2006). Undergraduate teaching of ideal and real fluid flows: the value of real-world experimental projects. European Journal of Engineering Education, 31(6), 729-739. doi: 10.1080/03043790600911837

Barcelos, N. N. S., Jacobucci, G. B., \& Jacobucci, D. F. C. (2010). Quando o cotidiano pede espaço na escola, o projeto da feira de ciências "Vida em Sociedade" se concretiza. Ciência \& Educação, 16(1), 215-233. doi: 10.1590/S1516-73132010000100013

Bargerhuff, M. E. (2013). Meeting the needs of students with disabilities in a STEM school. American Secondary Education, 41(3), 3-20.

Barron, B. J. S., Schwartz, D. L., Vye, N. J., Moore, A., Petrosino, A., Zech, L., \& Bransford, J. D. (1998). Doing with understanding: Lessons from research on problem and project-based learning. Journal of the Learning Sciences, 7(3), 271-311. doi: 10.1207/ s15327809jls0703\&4_2

Basu, S. J. (2008). Powerful learners and critical agents: The goals of five urban Caribbean youth in a conceptual physics classroom. Science Education, 92(2), 252-277. doi: 10.1002/ sce. 20241

Batista, I., Lavaqui, V., \& Salvi, R. (2008). Interdisciplinaridade escolar no ensino médio por meio de trabalho com projetos pedagógicos. Investigações em Ensino de Ciências, 13(2), 209-239. 
Bender, W. N. (2014). Aprendizagem Baseada em Projetos: educação diferenciada para o século XXI. Porto Alegre: PENSO.

Blumenfeld, P.C., Soloway, E., Marx, R. W., Krajcik, J.S., Guzdial, M., \& Palincsar, A. (1991). Motivating Project-Based Learning: Sustaining the Doing, Supporting the Learning. Educational Psychologist, 26(3-4), 369-398. doi: 10.1080/00461520.1991.9653139

Bonadiman, H., \& Nonenmacher, S. E. B. (2007). O gostar e o Aprender no Ensino de Física: Uma proposta metodológica. Caderno Brasileiro de Ensino de Física, 24(2), 194-223.

Chang, S. H., Chen, M. L., Kuo, Y. K., \& Shen, Y. C. (2011). A simulation-based LED design project in photonics instruction based on industry-university collaboration. IEEE Transactions on Education, 54(4), 582-589. doi: 10.1109/TE.2010.2098877

Chang, S. H., Wu, T. C., Kuo, Y. K., \& You, L. C. (2012). Project-based learning with an online peer assessment system in a photonics instruction for enhancing led design skills. Turkish Online Journal of Educational Technology, 11(4), 236-246.

Chue, S., \& Lee, Y.-J. (2013). The Proof of the Pudding?: A Case Study of an "At-Risk" Design-Based Inquiry Science Curriculum. Research in Science Education, 43(6), 24312454. doi: 10.1007/s11165-013-9366-X

Cole, M., Wilhelm, J., \& Yang, H. (2015). Student Moon Observations and SpatialScientific Reasoning. International Journal of Science Education, 37(11), 1815-1833. doi: 10.1080/09500693.2015.1052861

Cooper, H., Hedges, L., \& Valentine, J. (2009). The handbook of research synthesis and meta-analysis ( $2^{\mathrm{a}}$ ed.). New York: Russell Sage Foundation.

Dewey, J. (1899). School and society (Revised). Chicago: The University of Chicago Press. Recuperado de https://archive.org/details/schoolsociety00dewerich

Espín, J. J. C., Toledo, H. M. H., Vázquez, L. A. M., Hernández, J. O. M., Cielo, A. P., \& Martínez, V. P. (2015). Identificación de metales y no metales en las atmósferas de las estrellas . Un proyecto de colaboración docente del Instituto de Astronomía y del CCH Naucalpan para el curso de Química I. Latin American Journal of Physics Education, 9(S1), 1-9.

Espíndola, K., \& Moreira, M. A. (2006). Relato de uma experiência didática: ensinar Física com os projetos didáticos na EJA, estudo de um caso. Experiências em Ensino de Ciências, 1(1), 55-66.

Ezquerra, Á., Manso, J., Burgos, M. E., \& Hallabrin, C. (2014). Creation of audiovisual presentations as a tool to develop key competences in secondary-school students . A case study in science class. International Journal of Education and Development Using Information and Communication Technology, 10(4), 155-170. 
Fortus, D., Krajcik, J., Dershimer, R. C., Marx, R. W., \& Mamlok-Naaman, R. (2005). Design-based science and real-world problem-solving. International Journal of Science Education, 27(7), 855-879. doi: 10.1080/09500690500038165

Graaff, E. de, \& Kolmos, A. (2007). History of problem-based and project-based learning. In Management of Change Implementation of Problem-Based and Project-Based Learning in Engineering (pp. 1-8). Rotterdam: Sense. doi:10.1007/978-0-387-09829-6

Hazari, Z., Tai, R. H., \& Sadler, P. M. (2007). Gender differences in introductory university physics performance: The influence of high school physics preparation and affective factors. Science Education, 91(6), 847-876. doi: 10.1002/sce.20223

Helle, L., Tynjälä, P., \& Olkinuora, E. (2006). Project-based learning in post-secondary education - Theory, practice and rubber sling shots. Higher Education, 51(2), 287-314. doi: $10.1007 / \mathrm{s} 10734-004-6386-5$

Hernández, F. (1998). Transgressão e mudança na educação: os projetos de trabalho. Porto Alegre: Artmed.

Hernández, F., \& Ventura, M. (1998). A Organização do Currículo por Projetos de Trabalho: O conhecimento é um caleidoscópio ( $5^{\mathrm{a}}$ ed.). Porto Alegre: Artmed.

Hsu, P.-S., Van Dyke, M., Chen, Y., \& Smith, T. J. (2015). The effect of a graph-oriented computer-assisted project-based learning environment on argumentation skills. Journal of Computer Assisted Learning, 31(1), 32-58. doi:10.1111/jcal.12080

Ivanov, D., Nikolov, S., \& Petrova, H. (2014). Testing Bernoulli's law. Physics Education, 49(4), 436-442.

Jou, M., Chuang, C. P., \& Wu, Y. S. (2010). Creating interactive web-based environments to scaffold creative reasoning and meaningful learning: From physics to products. Turkish Online Journal of Educational Technology, 9(4), 49-57.

Kanter, D. E. (2010). Doing the Project and Learning the Content: Designing ProjectBased Science Curricula for Meaningful Understanding. Science Education, 94(3), 525551. doi: $10.1002 /$ sce. 20381

Knoll, M. (1997). The Project Method: Its Vocational Education Origin and International Development. Journal of Industrial Teacher Education, 34(3), 59-80.

Krajcik, J., McNeill, K. L., \& Reiser, B. J. (2008). Learning-goals-driven design model: Developing curriculum materials that align with national standards and incorporate project-based pedagogy. Science Education, 92(1), 1-32. doi: 10.1002/sce.20240

Langbeheim, E. (2015). A project-based course on Newton's laws for talented junior highschool students. Physics Education, 50(4), 410-415. doi: 10.1088/0031-9120/50/4/410

Lavaqui, V., \& Batista, I. de L. (2007). Interdisciplinaridade em ensino de ciências e de matemática no ensino médio. Ciência \& Educação, 13(3), 399-420. 
Machado, M. A. D., \& Queiroz, G. R. P. C. (2012). A Cultura de Projetos , Construída Via Parceria Escola- Universidade, Contribuindo para a Qualidade da Formação Inicial e Continuada de Professores. Revista Brasileira de Pesquisa Em Educação Em Ciências, 12(1), 93-116.

Macías-Guarasa, J., Montero, J. M., San-Segundo, R., Araujo, Á., \& Nieto-Taladriz, O. (2006). A project-based learning approach to design electronic systems curricula. IEEE Transactions on Education, 49(3), 389-397. doi: 10.1109/TE.2006.879784

Marino, L. A., Carreri, R. A., \& Alzugaray, G. E. (2006). Espacios curriculares como organizadores de contenidos en carreras biológicas : aportes desde la Física. Enseñanza de La Física, 19(1), 47-60.

Markham, T., Larmer, J., \& Ravitz, J. (2008). Aprendizagem baseada em Projetos: guia para professores de ensino fundamental e médio. (2 ${ }^{\text {a }}$ ed.). Porto Alegre: Artmed.

Mazur, E. (2015). Peer instruction: a revolução da aprendizagem ativa. Porto Alegre: Penso.

Meltzer, D. E., \& Otero, V. K. (2015). A brief history of physics education in the United States. American Journal of Physics, 83(5), 447-458. doi:10.1119/1.4902397

Menegotto, J. C., \& Rocha Filho, J. B. (2008). Atitudes de estudantes do ensino médio em relação à disciplina de Física. Revista Electrónica de Enseñanza de Las Ciencias, 7(2), 298-312.

Michaelsen, L. K., Knight, A. B., \& Fink, L. D. (2004). Team-Based Learning: A Transformative Use of Small Groups in College Teaching. Stylus.

Morales, C. A. C. (2009). Enseñanza de la conservación del momento angular por medio de la construcción de prototipos y el aprendizaje basado en proyectos. Latin American Journal of Physics Education, 3(2), 427-432.

Moura, D., \& Barbosa, E. F. (2013). Trabalhando com Projetos: Planejamento e gestão de projetos educacionais (8a ed.). Petrópolis: Vozes.

Novak, G., Gavrin, A., Christian, W., \& Patterson, E. (1999). Just-in-time teaching: blending active learning with web technology. Upper Saddle River: Prentice Hall.

Oliveira, C. L. (2006). A Metodologia de Projetos como recurso de ensino e aprendizagem na Educação Básica. CEFET-MG. Recuperado de http://www.tecnologiadeprojetos.com. br/banco_objetos/\%7B28A0E37E-294A-4107-906C-914B445E1A40\%7D_pedagogiametodologia.pdf

Parisoto, M. F., Moreira, M. A., \& Dröse, B. (2014). Integrating didactical strategies to facilitate meaningful learning in introductory college physics. Latin American Journal of Physics Education, 8(4), 1-7.

Prado, M.E. B. B. (2003). Pedagogia de Projetos. Gestão Escolar E Tecnologias. Recuperado de http://www.eadconsultoria.com.br/matapoio/biblioteca/textos_pdf/texto18.pdf 
Quintana-Nedelcos, A., \& Llovera-González, J. J. (2009). La Construcción del Conocimiento como Proceso Activo en la Enseñanza. Latin American Journal of Physics Education, 3(1), 153-157.

Raposo, W. L. (2014). História e Filosofia da Ciência na Licenciatura em Física, uma proposta de ensino através da pedagogia de projetos. Caderno Brasileiro de Ensino de Física, 31(3), 722-738. doi: 10.5007/2175-7941.2014v31n3p722

Rivet, A. E., \& Krajcik, J. S. (2008). Contextualizing Instruction: Leveraging Students' Prior Knowledge and Experiences to Foster Understanding of Middle School Science. Journal of Research in Science Teaching, 45(1), 79-100. doi:10.1002/tea.20203

Rosenfeld, M., \& Rosenfeld, S. (2006). Understanding teacher responses to constructivist learning environments: Challenges and resolutions. Science Education, 90(3), 385-399. doi: $10.1002 /$ sce. 20140

Sanders, N. E., Faesi, C., \& Goodman, A. a. (2014). A New Approach to Developing Interactive Software Modules Through Graduate Education. Journal of Science Education and Technology, 23(3), 431-440. doi:10.1007/s10956-013-9474-4

Schneider, R. M., Krajcik, J., \& Blumenfeld, P. (2005). Enacting reform-based science materials: The range of teacher enactments in reform classrooms. Journal of Research in Science Teaching, 42(3), 283-312. doi: 10.1002/tea.20055

Schnittka, C., \& Bell, R. (2011). Engineering Design and Conceptual Change in Science: Addressing thermal energy and heat transfer in eighth grade. International Journal of Science Education, 33(13), 1861-1887. doi:10.1080/09500693.2010.529177

Shemwell, J. T., Avargil, S., \& Capps, D. K. (2015). Grappling with long-term learning in science: A qualitative study of teachers' views of developmentally oriented instruction. Journal of Research in Science Teaching, 52(8), 1163-1187. doi:10.1002/tea.21239

Silva, L. M., Brizolla, F., \& Da Silva, L. E. (2013). Projeto pedagógico do curso de licenciatura em Ciências da UFPR Litoral: desafios e possibilidades para uma formação emancipatória. Revista Brasileira de Estudos Pedagógicos, 94(237), 524-541. Recuperado de http://www.scielo.br/pdf/rbeped/v94n237/a09v94n237.pdf

Thomas, J. W. (2000). A Review of Research on Project-Based Learning. The Autodesk Foundation, 1-49. Recuperado de http://www.bobpearlman.org/BestPractices/PBL Research.pdf

Tuyarot, D. E., \& Arriassecq, I. (2015). Enseñanza de la física universitaria a través de proyectos: el motor de Stirling. Revista de Enseñanza de La Física, 27(Extra), 447-452.

Venville, G., Sheffield, R., Rennie, L. J., \& Wallace, J. (2008). The writing on the wall: Classroom context, curriculum implementation, and student learning in integrated, community-based science projects. Journal of Research in Science Teaching, 45(8), 857880. doi: $10.1002 /$ tea. 20245 
Weizman, A., Shwartz, Y., \& Fortus, D. (2008). The Driving Question Board. The Science Teacher, 75(8), 47-55.

Yanitelli, M., Scancich, M., \& Pala, L. (2015). Análisis de propuestas didácticas que incorporan gráficas cartesianas. Revista de Enseñanza de La Física, 27(Extra), 17-25.

Zômpero, A., \& Laburú, C. (2011). Atividades investigativas no ensino de ciências: aspectos históricos e diferentes abordagens. Ensaio: Pesquisa Em Educação Em Ciências, 13(n. 3), 67-80. Recuperado de http://www.portal.fae.ufmg.br/seer/index.php/ensaio/ article/viewArticle/309

Terrimar Ignácio Pasqualetto

http://orcid.org/0000-0001-7921-5730 Instituto Federal do Rio Grande do Sul

Osório, Brasil

terrimar.pasqualetto@osorio.ifrs.edu.br

Eliane Angela Veit

http://orcid.org/0000-0002-2406-3415 Universidade Federal do Rio Grande do Sul

Instituto de Física Porto Alegre, Brasil eav@if.ufrgs.br

Ives Solano Araujo

${ }^{(0)}$ http://orcid.org/0000-0002-3729-0895 Universidade Federal do Rio Grande do Sul

Instituto de Física Porto Alegre, Brasil ives@if.ufrgs.br

Submetido em 14 de Julho 2016 Aceito em 15 de Abril 2017

Publicado em 31 de Agosto de 2017 